\title{
IL-18 promoter polymorphisms under scrutiny
}

\author{
Philipp G. Sand
}

Received: 18 April 2014/Accepted: 5 June 2014/Published online: 15 June 2014

(C) Springer Basel 2014

To the Editors,

In their recent contribution to this journal, $\mathrm{Li}$ and coworkers investigated the pooled effects of two $I L-18$ gene variants in periodontitis. Based on data from 576 cases and 458 controls, they claim significant associations for both variants with the phenotype under study. At closer inspection, however, this claim is not tenable.

First, the literature search conducted by the authors misses key investigations including the largest study published [1]. Of the three studies that were retrieved by $\mathrm{Li}$ et al., two clearly feature overlapping control populations, yet were counted as separate samples [2, 3].

Second, information from earlier studies is grossly misinterpreted. Thus the risk-lowering effect of the minor allele at rs187238 [4] was mistaken for a risk-enhancing effect causing further bias in the allelic and genotypic models (see forest plots in [5]). When the authors refer to the "C" allele at rs187238, this corresponds to the " $G$ " allele on the forward DNA strand (reference by consensus, as in [6]) as the primers in all three investigations align to the reverse strand.

Power calculations presented in Table 1 [5] are in error: the individual studies were massively underpowered for both SNPs. For example, for rs1946519 in [2], a power of $<0.05$, not 0.83 , was achieved.

Finally, the authors have merged information from rs187238 and rs1946519 for sensitivity and publication bias analyses in Figs. 4 and 5 [5]. This is not legitimate as the two SNPs are not in tight linkage disequilibrium and cannot be considered surrogate markers.

On the whole, the methodology employed by $\mathrm{Li}$ et al. is far from convincing. I invite the authors to resolve the above issues so that the true overall effect of the candidate $I L-18$ variants may be appreciated.

\section{References}

1. Martelli FS, Mengoni A, Martelli M, Rosati C, Fanti E. IL-18 gene promoter polymorphisms are only moderately associated with periodontal disease in Italian population. Clin Cases Miner Bone Metab. 2012;9:153-6.

2. Noack B, Görgens H, Lorenz K, Schackert HK, Hoffmann T. TLR4 and IL-18 gene variants in chronic periodontitis: impact on disease susceptibility and severity. Immunol Invest. 2009;38: 297-310.

3. Noack B, Görgens H, Lorenz K, Ziegler A, Hoffmann T, Schackert HK. TLR4 and IL-18 gene variants in aggressive periodontitis. J Clin Periodontol. 2008;35:1020-6.

4. Folwaczny M, Glas J, Török HP, Tonenchi L, Paschos E, Bauer B, Limbersky O, Folwaczny C. Polymorphisms of the interleukin-18 gene in periodontitis patients. J Clin Periodontol. 2005;32:530-4.

5. Li ZG, Li JJ, Sun CA, Jin Y, Wu WW. Interleukin-18 promoter polymorphisms and plasma levels are associated with increased risk of periodontitis: a meta-analysis. Inflamm Res. 2014;63: $45-52$.

6. Ensembl database, http://www.ensembl.org, accessed April 2014.

Responsible Editor: Ji Zhang.

P. G. Sand $(\bowtie)$

Department of Psychiatry, University of Regensburg,

Regensburg, Germany

e-mail: philipp.sand@klinik.uni-regensburg.de 